openUP

\title{
CAN LEADING BUSINESS CYCLE INDICATORS PREDICT THE DIRECTION OF THE SOUTH AFRICAN COMMERCIAL SHARE PRICE INDEX?
}

\author{
ELNA MOOLMAN AND JOHANNES JORDAAN
}

\begin{abstract}
Leading indicators are a popular way to predict turning points in the business cycle. However, since the lead time of these indicators differ, those with a longer lead could potentially also be used to predict turning points in other leading indicators. This paper empirically explores the viability of using leading indicators to predict the turning points of an index of commercial shares on the JSE Securities Exchange. Although share prices are leading the business cycle, other leading indicators that lead the business cycle by a longer period should lead share prices and, therefore, could potentially be useful in predicting the direction of share price movements.

The objective of this study is to evaluate and compare the performance of different leading indicators in leading the commercial share price index and in predicting turning points in the commercial share price index. In addition, a multivariate logit model is developed and estimated using these leading indicators in an attempt to improve the accuracy of forecasting the direction of the commercial share index.
\end{abstract}

\section{INTRODUCTION}

THE CONCEPT OF BUSINESS CYCLES has its origins as a distinct phenomenon in the observation of significant indicators that describe the economic process and activity. This process is not constant and is characterised by cumulative upward and downward movements in which observers claim to discern certain regularities (Oppenlander, 1997:3). In economic activity a distinction can be made between many different types of cyclical behaviour, including leading, coincident and lagging indicators. Leading economic indicators have the characteristic of predicting turning points in economic activity. Leading indicators were originally proposed in 1938 by Mitchell and Burns because of their tendency to lead the cycle and detect and predict business cycle turning points (Del Negro, 2001:3).

Research in the late 1960s and early 1970s made cautious reference to the potential use of some leading economic time series in stock price forecasting models (see e.g. Bowyer, 1967:457-481; Brealey, 1969:34-35 and Latane and Tuttle, 1970:293-302). By definition the cycles in leading indicators lead the cycles in economic growth by a fixed period. Since the cyclical behaviour of all leading indicators has a fixed relationship with the business cycle, the relationships between the cycles of different leading indicators must also be fixed. Therefore, leading indicators could potentially be used to predict turning points in each other, since leading indicators should also be leading those that lead the business cycle by shorter periods. 
Heathcotte and Apilado (1974:247) were the first to conduct empirical research on the predictive usefulness of such series. According to them, all the other leading indicators on the 1966 Short List of the National Bureau of Economic Research (NBER) have historically led business cycle peaks by median numbers of months greater than that by which stock prices have led peaks, and that two series (new building permits, private housing units and change in book value; and manufacturing and trade investment) have led business cycle troughs by median numbers of months greater than stock prices.

It has been shown that leading indicators can be used successfully to predict turning points in the South African business cycle (Moolman 2003). However, Moolman (2003) also shows that the commercial share price index leads the business cycle by six months while, for example, the nominal effective exchange rate and the composite index of leading indicators of South Africa's trading partners ${ }^{3}$ leads the business cycle by 24 months. These two leading indicators should therefore also lead the commercial share price index. This paper empirically explores the viability of using leading indicators to predict the turning points of an index of commercial shares on the JSE Securities Exchange. Although share prices are leading the business cycle, other leading indicators that lead the business cycle by a longer period should lead share prices and could therefore potentially be useful in predicting the direction of share price movements.

The objective of this study is to evaluate and compare the performance of different leading indicators in leading the commercial share price index. This information is then used to construct a leading index to predict turning points in the commercial share price index. Following Heathcotte and Apilado (1974), the relationships between the commercial share price index and the other leading indicators will be analysed on empirical rather than theoretical grounds. The performance of the estimated model is compared with other models.

This article is organised as follows: the individual indicators analysed are discussed in section 2, while the empirical results are explained in section 3; section 4 provides some conclusions.

\section{LEADING INDICATORS}

Leading economic indicators can provide an indication of the timing of business cycle turning points for sound economic reasons, as dictated by economic theory (Klein, 1997:42). Investors, consumers and governments may attempt to anticipate possible market changes or respond to market changes, which will change supply and demand conditions and influence the overall state of the economy, for instance, through building permits for new houses, real estate transactions, the number of new cars sold, percentage of people working overtime and so forth (Lindlbauer, 1997:75-87). In addition to having a constant historical relationship with the business cycle, leading indicators have to be published in time to take advantage of the existing predictive content (Heathcotte and Apilado, 1974:247). Further, it must be final data (i.e. not revised later) and be available monthly. Popular leading indicators include: building permits; the value of residential buildings passed; manufacturers' new orders; the tradeweighted exchange rate; international business cycle indicators such as the composite index of leading indicators of the country's main trading partners; gold and foreign

\footnotetext{
${ }^{3}$ Constructed by the South African Reserve Bank.
} 
exchange reserves; oil prices; consumer credit; passenger car sales; and stock prices. ${ }^{4}$

It has become increasingly difficult to identify a single economic variable that can help to gauge and predict economic activity. Indicators may often give conflicting signals, for example, consumer sentiment may be plummeting while building permits for new houses are increasing. Thus, it is not advisable for an investor to rely solely on one or two of these series in attempting to predict the future course of stock prices. Rather, a diffusion index or a composite index of leading indicators can be constructed that incorporates all the series' movements into a single index - in other words, a weighted average of leading indicators (Del Negro, 2001:4, Heathcotte and Apilado, 1974:249 and Shbikat, 2000:11).

\section{EMPIRICAL ANALYSIS}

(a) The logit technique

Several authors have used logit or probit models to model business cycle turning points (see e.g. Estrella and Hardouvelis, 1991; Dueker, 1997; Dotsey, 1998; Estrella and Mishkin, 1998; Bernard and Gerlach, 1996). The logit or probit form is dictated by the fact that the variable being predicted takes on only two possible values - whether the economy is in a recession or not. The model is defined with reference to a theoretical linear relationship of the form:

$\mathrm{Y}_{\mathrm{t}+\mathrm{k}}^{*}=\alpha+\beta^{*} \mathrm{x}_{\mathrm{t}}+\varepsilon_{\mathrm{t}}$

where $Y_{t}^{*}$ is an unobservable factor that determines the occurrence of a recession at

time $\mathrm{t}, \mathrm{k}$ is the length of the forecast horizon, $\varepsilon_{t}$ is a normally distributed error term and $\mathrm{x}_{\mathrm{t}}$ the value of the explanatory variable at time t. The parameters $\alpha$ and $\beta$ are estimated with maximum likelihood. The observable recession indicator $\mathrm{R}_{\mathrm{t}}$ is related to this model by

$$
\mathrm{R}_{\mathrm{t}}=1 \text { if } \mathrm{Y}_{\mathrm{t}}^{*}>0 \text {, and } 0 \text { otherwise }
$$

The form of the estimated equation is

$$
P\left(R_{t+k}=1\right)=F\left(\alpha+\beta^{*} x_{t}\right)
$$

where $\mathrm{F}$ is the cumulative logistic distribution function. The model is estimated by maximum likelihood.

In this study, instead of modelling turning points in the business cycle, turning points in the commercial share price index will be modelled. In other words, in equations 2 and 3 the recession indicator $R_{t}$ takes on the value 1 if the commercial share price index is declining in period $\mathrm{t}$, and 0 otherwise.

(b) Indicators examined and data used

The primary focus of this paper is to compare the performance of individual economic indicators in predicting turning points in the commercial share price index. The leading indicators that will be examined are listed in Table 1. All the data were obtained from the Quarterly Bulletin of the South African Reserve Bank. Monthly data for the period

\footnotetext{
${ }^{4}$ See, for example, Heathcotte and Apilado (1974:249), Van Coller (1980:41-73), Lindlbauer (1997:160), Shbikat (2000:12), Del Negro (2001:4), Snyman (1994) and Renshaw (1992:132).
} 
openUP

March 1978 to April 2001 were used in the empirical analysis ${ }^{5}$. Forecasts for 1 to 24 months ahead, in other words up to two years, were considered.

Table 1. List of variables

\begin{tabular}{lll}
\hline Series & Description & Transformation used $^{6}$ \\
RS & $\begin{array}{l}\text { Interest rates } \\
\text { Short-term nominal interest rate }\end{array}$ & \\
RL & Long-term nominal interest rate & \\
SPR & $\begin{array}{l}\text { Yield spread, defined as the difference between the long- and short-term } \\
\text { interest rates }\end{array}$ & \\
& Monetary aggregates & Year on year growth \\
M3 & Nominal M3 money supply & Year on year growth \\
M2 & Nominal M2 money supply & Year on year growth \\
M1 & Nominal M1 money supply & Year on year growth \\
CL & Construction loans & \\
& International indicators & Year on year growth \\
NEE & Nominal effective exchange rate & Year on year growth \\
R\$ & Rand-US\$ exchange rate & Year on year growth \\
TR & Composite index of leading indicators of trading partners & \\
& Macroeconomic indicators & Year on year growth \\
BP & Building plans passed & Year on year growth \\
NO & Manufacturing, new orders & Year on year growth \\
CIL1 & Composite Index of Leading Indicators & Percentage change \\
CIL2 & Composite Index of Leading Indicators & Level \\
SB1 & SACOB Business Confidence Index & Percentage change \\
SB2 & SACOB Business Confidence Index &
\end{tabular}

Price indices for all classes of shares have been calculated by the Reserve Bank using information obtained from the JSE Securities Exchange since January 1969. In calculating the price indices, the shares are grouped into 24 sub-categories and 12 combined categories, including the three main categories of mining, financial and industrial and commercial shares, as well as all classes of shares (SARB, 1993:2). The data from the South African Reserve Bank does not fully correspond to the classification used by the JSE Securities Exchange, because certain companies have been reclassified according to their principal activity. Listed companies are used according to market capitalisation weight. The index is based on monthly average prices per company (SARB, 1993). Fig. 1 plots the commercial share price index from 1978 to 2001 (on the left axis), with the constructed variable R that takes on the value 1 if the commercial share price index is declining, and 0 if the index is increasing (on the right axis).

5 The sample period was chosen to match that in Moolman (2003) to ensure comparability of the correlation coefficients and other results. The sample period was regarded as sufficiently long and recent for the estimation part of the analysis, while leaving enough observations for the out-of-sample evaluation.

${ }^{6}$ With all the variables the level, the year-on-year growth and the growth from the preceding period was used. The transformations listed here refer to the best performing transformation of each variable. 


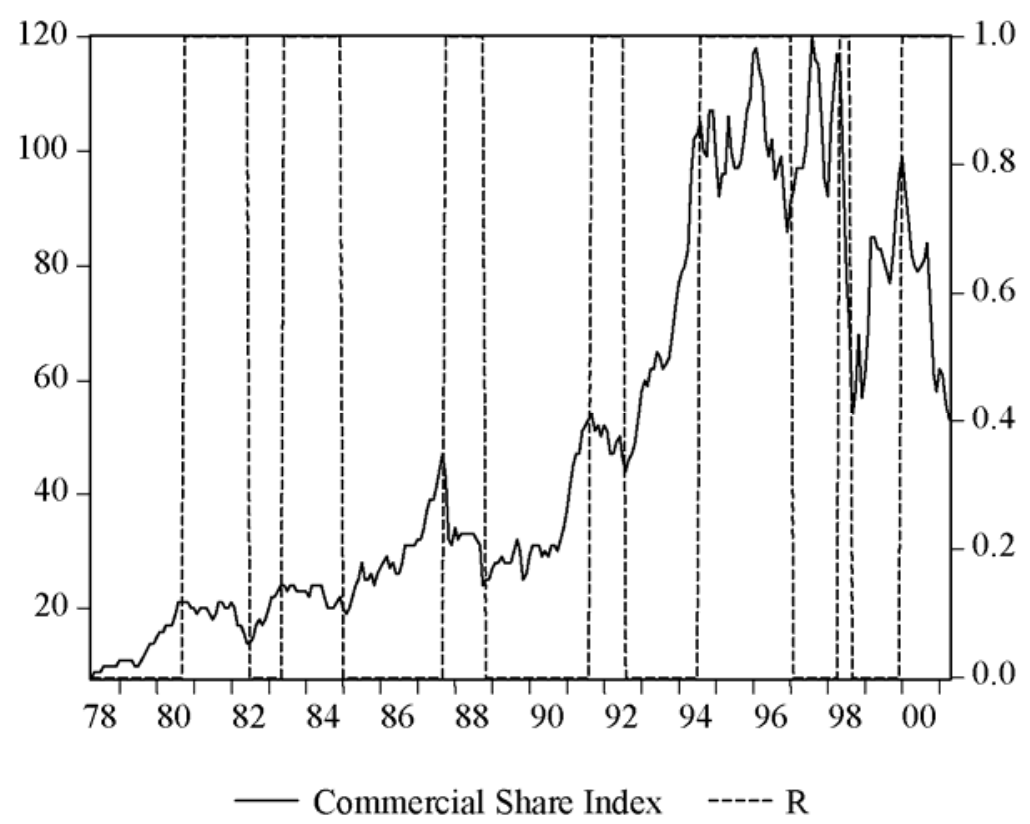

Figure 1. Turning points in the commercial share price index

(c) Performance of Individual Leading Indicators

In the case of models with dichotomous dependent variables, the standard $\mathrm{R}^{2}$ is invalid as a model selection criterion. Therefore, McFadden's pseudo $\mathrm{R}^{2}$ was used to compare the forecast performance of individual leading indicators in forecasting business cycle

turning points for 1 to 24 months ahead. This pseudo $R^{2}$ is calculated as $1-\frac{\ell(\hat{\beta})}{\ell(\widetilde{\beta})}$

where $\ell(\widetilde{\beta})$ is the unrestricted log likelihood and the $\ell(\hat{\beta})$ restricted log likelihood.

The interpretation of this pseudo $R^{2}$ is analogous to that of the $R^{2}$ reported in linear regression models. The McFadden pseudo ${ }^{2}$-values of the models are given in Table 2 . The highest $\mathrm{R}^{2}$ value of each series is indicated in bold print. For example, the highest

$R^{2}$ value when the yield spread is used as explanatory variable is 7,3 per cent, which is obtained for a lead of 14 months. Therefore, the optimal lead period of the yield spread for predicting the commercial share price index is considered to be 14 months.

From the results in Table 2 it is clear that the year-on-year growth in the nominal effective exchange rate (leading eighth months) has the highest $\mathrm{R}^{2}$ value (23 per cent), followed by the growth in M2 money supply (leading 18 months with an $\mathrm{R}^{2}$ of 17 per cent), the annual change in the rand/US\$ exchange rate (leading 12 months with an $\mathrm{R}^{2}$ of 17 per cent) and the growth in building plans passed (leading eight months with an $\mathrm{R}^{2}$ of 16 per cent). Each of these variables explains more than 16 per cent of the variation in the dependent variable.

Different combinations of the leading indicators were evaluated using two criteria: McFadden's $\mathrm{R}^{2}$, the equivalent in the case of a dichotomous dependant variable to the normal $\mathrm{R}^{2}$; and an arbitrary probability threshold. Here the assumption was made that if the model predicted a probability of more than (below) 50 per cent it was signalling a decline (an increase) in the commercial share index ${ }^{7}$. 
openUP

Table 2. Pseudo $\mathrm{R}^{2}$-values of leading indicators

\begin{tabular}{|c|c|c|c|c|c|c|c|c|}
\hline Lead months & RS & RL & SPR & M3 & M2 & M1 & CL & NEE \\
\hline 1 & 0.0 & 0.8 & 0.3 & 2.4 & 6.0 & 14 & 20.8 & 1.0 \\
\hline 2 & 0.0 & 0.3 & 0.0 & 2.2 & 5.0 & 13 & 21.2 & 3.0 \\
\hline 3 & 0.0 & 0.0 & 0.3 & 2.2 & 4.0 & 12 & 20.9 & 6.3 \\
\hline 4 & 0.0 & 0.0 & 1.0 & 2.0 & 3.0 & 10 & 21.6 & 10 \\
\hline 5 & 0.0 & 0.1 & 2.0 & 1.6 & 2.0 & 7.7 & 18.7 & 15 \\
\hline 6 & 0.0 & 0.4 & 2.7 & 1.2 & 1.6 & 6.5 & 13.4 & 20 \\
\hline 7 & 0.0 & 0.9 & 3.3 & 0.7 & 0.8 & 5.0 & 11.1 & 23 \\
\hline 8 & 0.0 & 0.1 & 3.9 & 0.2 & 0.1 & 3.0 & 6.8 & 23 \\
\hline 9 & 0.1 & 0.2 & 4.4 & 0.0 & 0.0 & 2.0 & 3.5 & 22 \\
\hline 10 & 0.1 & 0.3 & 4.9 & 0.0 & 0.1 & 0.1 & 1.3 & 21 \\
\hline 11 & 0.1 & 0.3 & 5.5 & 1.0 & 2.7 & 0.0 & 1.1 & 19 \\
\hline 12 & 0.1 & 3.6 & 6.3 & 2.0 & 5.0 & 0.2 & 0.4 & 17 \\
\hline 13 & 0.1 & 3.6 & 7.0 & 3.0 & 7.5 & 0.1 & 0.2 & 13 \\
\hline 14 & 0.1 & 3.6 & 7.3 & 5.0 & 11 & 2.0 & 0.2 & 9.6 \\
\hline 15 & 0.1 & 3.2 & 7.0 & 6.8 & 13 & 3.0 & 0.0 & 5.3 \\
\hline 16 & 0.1 & 2.6 & 7.0 & 8.0 & 15 & 3.0 & 0.1 & 2.1 \\
\hline 17 & 7.5 & 2.5 & 6.3 & 9.0 & 16 & 4.0 & 0.2 & 0.4 \\
\hline 18 & 7.0 & 2.5 & 5.6 & 10 & 17 & 4.0 & 0.3 & 0.0 \\
\hline 19 & 6.2 & 2.7 & 4.5 & 10 & 16 & 4.0 & 0.8 & 0.0 \\
\hline 20 & 5.6 & 3.2 & 3.0 & 10 & 16 & 5.0 & 1.0 & 0.3 \\
\hline 21 & 4.9 & 3.8 & 2.5 & 9.8 & 14 & 5.0 & 1.5 & 0.5 \\
\hline 22 & 4.3 & 4.0 & 1.8 & 8.6 & 12 & 5.0 & 1.5 & 0.8 \\
\hline 23 & 3.4 & 3.9 & 1.1 & 7.0 & 10 & 5.0 & 1.3 & 1.2 \\
\hline 24 & 2.7 & 3.7 & 0.6 & 5.7 & 9.0 & 6.0 & 1.1 & 1.6 \\
\hline Lead months & RS & TR & BP & NO & CIL1 & CIL2 & SB1 & SB2 \\
\hline 1 & 0 & 0.4 & 5.0 & 5.0 & 0.0 & 3.5 & 11 & 2.7 \\
\hline 2 & 0.2 & 1.0 & 8.0 & 6.0 & 0.2 & 2.0 & 12 & 6.3 \\
\hline 3 & 1.0 & 2.0 & 9.0 & 6.0 & 0.8 & 1.0 & 12 & 8.9 \\
\hline 4 & 3.0 & 2.0 & 11 & 7.5 & 2.0 & 0.5 & 11 & 11.7 \\
\hline 5 & 6.0 & 2.0 & 14 & 7.0 & 3.0 & 0.2 & 9.0 & 13.7 \\
\hline 6 & 9.0 & 2.0 & 14 & 6.0 & 4.0 & 0.0 & 8.0 & 15.7 \\
\hline 7 & 11 & 2.6 & 15 & 5.0 & 5.0 & 0.2 & 7.0 & 16.9 \\
\hline 8 & 13 & 2.8 & 16 & 3.0 & 6.0 & 0.4 & 5.7 & 16.2 \\
\hline 9 & 15 & 2.7 & 15 & 3.0 & 6.5 & 1.0 & 5.0 & 15.2 \\
\hline 10 & 16 & 2.0 & 15 & 2.0 & 7.0 & 1.0 & 4.0 & 13.5 \\
\hline 11 & 16 & 2.0 & 12 & 2.0 & 7.0 & 2.0 & 2.0 & 11.1 \\
\hline 12 & 17 & 1.0 & 11 & 1.0 & 7.0 & 2.0 & 1.0 & 9.1 \\
\hline 13 & 16 & 1.0 & 9.0 & 1.0 & 6.5 & 4.0 & 0.4 & 7.2 \\
\hline 14 & 14 & 0.3 & 7.0 & 0.5 & 5.5 & 3.0 & 0.0 & 5.4 \\
\hline 15 & 10 & 0.1 & 5.0 & 0.0 & 5.0 & 3.0 & 0.2 & 3.4 \\
\hline 16 & 6.0 & 0.0 & 4.0 & 0.0 & 4.0 & 3.0 & 0.1 & 1.1 \\
\hline 17 & 4.0 & 0.0 & 2.0 & 0.0 & 3.0 & 2.0 & 0.2 & 0.3 \\
\hline 18 & 20 & 0.3 & 1.0 & 0.0 & 3.0 & 3.0 & 3.6 & 0.0 \\
\hline 19 & 1.0 & 0.9 & 1.0 & 0.1 & 2.0 & 3.0 & 5.0 & 0.0 \\
\hline 20 & 1.0 & 1.6 & 1.0 & 0.3 & 1.0 & 3.0 & 5.0 & 0.0 \\
\hline 21 & 0.4 & 2.3 & 1.0 & 0.3 & 1.0 & 2.0 & 5.0 & 0.0 \\
\hline 22 & 0.4 & 3.0 & 1.0 & 0.2 & 0.2 & 2.0 & 6.0 & 0.0 \\
\hline 23 & 0.4 & 3.0 & 1.0 & 0.1 & 0.0 & 1.0 & 6.0 & 0.0 \\
\hline 24 & 0.4 & 3.0 & 1.0 & 0.1 & 0.0 & 0.4 & 6.0 & 0.0 \\
\hline
\end{tabular}

${ }^{7}$ The probability was never exactly 50 per cent. 
Each of the variables was assumed to lead the commercial share price index with the number of months that yielded the highest $\mathrm{R}^{2}$ in Table 2 . For example, the nominal effective exchange rate was assumed to lead the commercial share price index by eight months while the growth in money supply (Ml) was assumed to lead the commercial share price index by one month. Table 3 presents the results of the final multivariate logit model.

\section{Table 3. Multivariate logit model}

\begin{tabular}{|c|c|c|c|}
\hline \\
\hline \multicolumn{4}{|c|}{$\begin{array}{l}\text { Dependent vaniable: } R_{\mathrm{t}} \\
\text { Method: ML - binary logit (quadratic hill climbing) }\end{array}$} \\
\hline \multicolumn{4}{|c|}{ Covariance matrix computed using second derivatives } \\
\hline Variable $^{8}$ & Coefficient & & p-value \\
\hline Constant & 0.78 & & 0.10 \\
\hline $\mathrm{BP}(-8)$ & 4.20 & & 0.00 \\
\hline $\mathrm{ON}(-5)$ & 10.40 & & 0.00 \\
\hline $\operatorname{NEE}(-8)$ & 19.80 & & 0.00 \\
\hline $\mathrm{R} \$(-12)$ & -12.5 & & 0.00 \\
\hline M1(-1) & 3.84 & & 0.09 \\
\hline $\operatorname{CIL} 1(-4)$ & 0.29 & & 0.00 \\
\hline $\operatorname{SPR}(-14)$ & -0.47 & & 0.00 \\
\hline $\mathrm{SB} 2(-7)$ & 9.98 & & 0.06 \\
\hline Mean dependent var & 0.42 & McFadden $\mathrm{R}^{2}$ & 0.54 \\
\hline
\end{tabular}

All the explanatory variables in all the models are significant at a 10 per cent level of significance. The results in Table 3 are interpreted as follows:

$$
\begin{aligned}
& \mathrm{P}\left(\mathrm{R}_{\mathrm{t}}=1\right)=\mathrm{F}(0.78+4.20 * \mathrm{BP}(-8)+10.40 * \mathrm{ON}(-5)+19.80 * \mathrm{NEE}(-8)-12.50 * \mathrm{R} \$(-12)+3.84 * \mathrm{M} 1(- \\
& 1)+0.29 * \mathrm{CIL} 1(-4)-0.47 * \mathrm{SPR}(-14)+9.98 * \mathrm{SB} 2(-7))
\end{aligned}
$$

where $\mathrm{F}$ is the cumulative logistic distribution, $\mathrm{R}_{\mathrm{t}}$ is a dummy variable that takes on the value one if the commercial share price index is declining in period $t$, and $P\left(R_{t+i}=1\right)$ is

the probability that the commercial share price index is declining in period $t$. With this model, the probability that the commercial share price index will decline in a particular period can be calculated a month in advance.

Fig. 2 plots the estimated probability that the commercial share price index is declining in each period ("fitted"). The "actual" line in Fig. 2 illustrates the actual movements of the commercial share price index, by taking on the value 1 when the commercial share price index declined and 0 when it increased. The "fitted" line in Fig. 2 illustrates the probability that the commercial share price index declined as predicted by the model in Table 3. If this model is useful in predicting the direction of the commercial share price index, the predicted probability should be close to one (zero) in periods during which the commercial share price index declined (increased). Fig. 2 illustrates that the predicted probability in each period is usually high (low) in periods during which the commercial share price index declined (increased). This indicates that the model in Table 3 is indeed useful in tracking the direction of the commercial share price index.

If the assumption is made that the commercial share index is declining when the predicted probability is less than 50 per cent and increasing when the predicted probability is above 50 per cent, the model correctly predicted the direction of the index 86 per cent of the time (see Table 4). The final multivariate logit model was

\footnotetext{
${ }^{8}$ The trans formations listed in Table 2 were used.
} 
chosen on the basis of the (McFadden) $\mathrm{R}^{2}$ and the percentage of correct predictions regarding the direction of the commercial share index. This model outperformed other combinations of the leading indicators as discussed earlier.

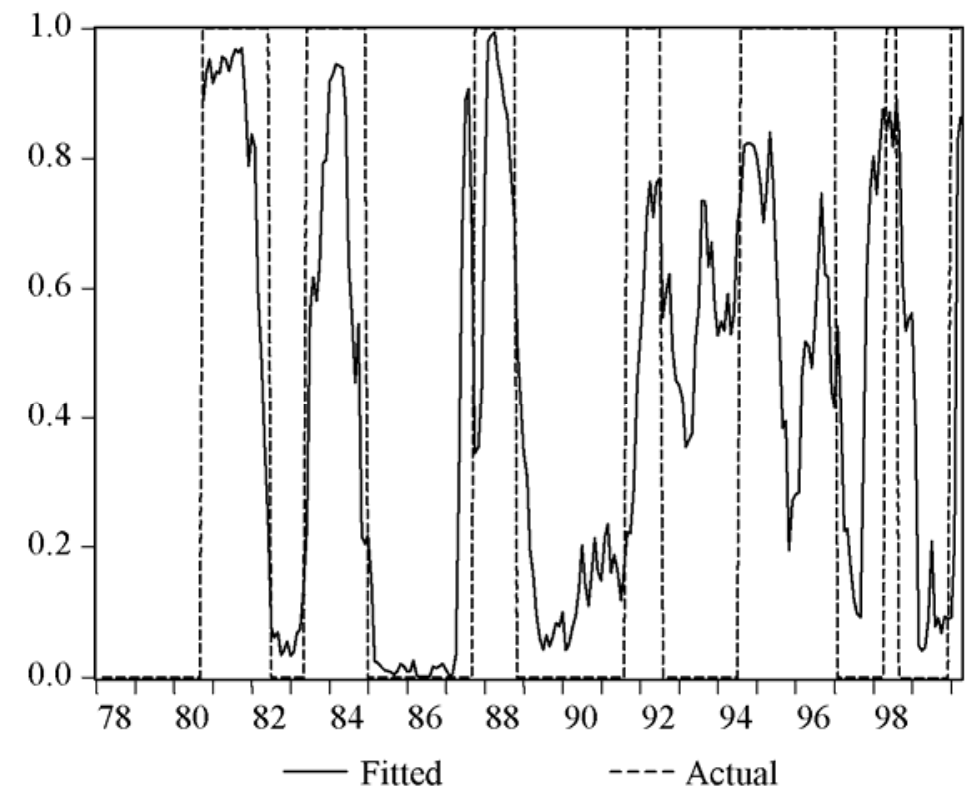

Figure 2. Actual and predicted declines of the commercial share price index

(d) Evaluation of the multivariate logit model

These estimated probabilities could be used to construct a trading rule according to which investors can buy or sell the commercial share index. For example, since investors would like to buy at the troughs and sell at the peaks of share prices, one possible trading rule would be to invest in commercial shares if they are more likely to increase than decline in a particular period. In other words, investors would sell their commercial shares when the probability of a downturn in the commercial share price index exceeds 50 per cent, while they would buy commercial shares when the probability of a downturn in the commercial share price index is below 50 per cent. If this rule had been applied over the sample period, the model would have predicted the direction of the commercial share price index correctly for 86 per cent of the observations.

However, it is generally assumed that investors are risk averse (Reilly, 1989:10,255; Renwick, 1971:400) and this could be reflected in the trading rule. For example, instead of acting on probabilities below and above 50 per cent, investors may prefer to risk selling their shares unnecessarily and forego some potential profit to the risk of buying or holding shares and making losses when their prices are declining. In this case investors would base their investment actions on a threshold probability of a fall in the commercial share price index below 50 per cent. For example, the threshold probability might be 40 per cent, in which case investors will buy (sell) commercial shares when the probability of a downturn in the commercial share price index is below (above) 40 per cent. Using this rule over the sample period, investors would have taken the "correct" decision. In other words, they would have sold (bought) commercial shares while the index was declining (rising), for 85 per cent of the months. The thresholds of 40 and 50 
per cent were chosen arbitrarily.

Table 4 presents the percentage and number of times investors would have taken the correct action (i.e. sold (bought) commercial shares while the index was declining (rising)) for several potential threshold probabilities.

Table 4. Comparative performance of different trading rules

\begin{tabular}{lll}
\hline Threshold & \% Correct (in-sample) & \% Correct (out-of-sample) \\
0.30 & 84 & 100 \\
0.35 & 85 & 100 \\
0.40 & 85 & 100 \\
0.45 & 84 & 100 \\
0.50 & 86 & 100 \\
\hline
\end{tabular}

The results in Table 4 illustrate that the model performs relatively well under the chosen loss functions, being correct regarding the direction of the commercial share index more than 84 per cent of the time. Obviously, investors should ideally test the performance of the model given their specific loss functions. The loss functions explored here are merely for illustrative purposes.

Four potential models or strategies were considered for predicting the direction of the commercial share price index :

(i) The logit model derived above. It is assumed that the model indicates a decline in commercial share prices when the probability of a downturn in the commercial share price index exceeds 50 per cent, while it is assumed to indicate an upturn in commercial share prices when the probability of a downturn in the commercial share price index is below 50 per cent.

(it) A moving-average. One of the most popular averages used to identify major stock market trends is the 200-day (or 30-week) moving average (Jones 1991:438). The moving average line is used to create a basic trend line of stock prices. A general sell (buy) signal is created when the actual stock price index falls below (rises through) the moving average line.

(Hi) A vector autoregression (VAK) model, which includes all the variables in the final logit model.

(iv) The final strategy is based on lagged changes in the commercial share price index. If commercial share prices fell (rose) in the preceding period, they are assumed to fall (rise) again in the current period.

Table 5. Comparing model accuracy

\begin{tabular}{lll}
\hline Strategy & $\%$ Correct (in-sample) & \% Correct (out-of-sample) \\
(i) & 86 & 100 \\
(ii) & 26 & 38 \\
(iii) & 14 & 25 \\
(iv) & 65 & 67 \\
\hline
\end{tabular}

The results in Table 5 indicate that the logit model derived in this paper performs relatively well in predicting the direction of the commercial share index both in-sample as well as outof-sample. However, the incredible out-of-sample accuracy of the model by no means implies that it can be expected to have 100 per cent forecasting accuracy. Indeed, it was less accurate during the sample period (see Table 4). Rather, the results in Table 5 should be viewed merely as a ranking of the various models during a specific period. Admittedly, the period was relatively short and there was only a single change in 
the direction of the commercial share prices index. There may be economic or other factors that impact on the models' relative performances, for example, some may perform better in bull (bear) markets or during recessions (expansions), so that the models' performances might not be the same if a different period is selected. However, this type of analysis falls outside the scope of the current study. The comparison above is intended simply as an illustration of the usefulness of the model over an arbitrary period and when compared to relatively naive and arbitrarily selected models.

\section{CONCLUSION}

This paper evaluated the performance of various leading economic indicators to predict the direction of the commercial share price index. Although the overall share price index is a leading indicator of the business cycle, it is possible that other leading indicators can lead the prices of specific groups of shares such as commercial shares. In addition, a composite index to predict the direction of the commercial share price index was constructed using the best performing individual leading indicators. The results of the empirical analysis show that the best composite model includes the following variables: building plans, new orders, nominal effective exchange rate, the rand/US\$ exchange rate, money supply, the composite index of leading indicators, the yield spread and Sacob's business confidence index. The constructed index predicted the direction of the commercial share price index correct for 86 per cent of the observations.

\section{REFERENCES}

BERNARD, H. AND GERLACH, S. (1996). "Does the term structure predict recession? The international evidence", Bank for International Settlements Working Paper No 37.

BOWYER, J.W. (1967). Investment Analysis and Management, $4^{\text {th }}$ ed. Homewood: Richard D. Irwm, Inc. BREALEY, R.A. (1996). An Introduction to Risk and Return from Common Stocks. Cambridge: MIT Press. CAPITAL MARKET STATISTICS OF SOUTH AFRICA 1938-1992. (1993). Supplement to the South African Reserve Bank Quarterly Bulletin (SARBQB). December. DEL NEGRO, M. (2001). "Turn, Turn, Turn: Predicting Turning Points in Economic Activity". Federal Reserve Bank of Atlanta Economic Review, Second Quarter: 1-12

DUEKER, M.J. (1997). "Strengthening the case for the yield curve as a predictor of US recessions", Federal Reserve Bank of St. Eouis Review, 79: 41-51.

DOTSEY, M. (1998). "The predictive content of the interest rate term spread for future economic growth", Federal Reserve Bank of Richmond Economic Quarterly, 84: 31-51.

ESTRELLA, A. AND HARDOUVELIS, G.A. (1991). "The Term Structure as a Predictor of Real Economic Activity" The Journal of Finance, 46:555-575.

ESTRELLA, A., AND MISHKIN, F.S. (1998). "Predicting U.S. recessions: financial variables as leading indicators", The Review of Economics and Statistics, 80:45-60.

HEATHCOTTE, B. AND APILADO, V.P. (1974). "The Predictive Content of Some Leading Economic Indicators for Future Stock Voices". Journal of Financial and Quantitative Analysis. March, 247-258 JONES, C.P. (1991). Investments: Analysis and Management. New York: Wiley.

KLEIN, P.A. (1997). The theoretical basis of cyclical indicators. Business Cycle Indicators. Edited by Oppenlander, K.H. England: Antony Rowe Ltd.

LATANE, H.A. AND TUTTLE, D.A. (1970). Security Analysis and Portfolio Management. New York: The Ronald Press Company.

LINDLBAUER, J.D. (1997). Assessment of selected leading indicators. Business Cycle Indicators. Edited by Oppenlander, K.H. England: Antony Rowe Ltd.

MOOLMAN, E. (2003). Predicting turning points in the South African economy. South African Journal of Economic and Management Sciences, forthcoming.

OPPENLANDER, K.H. (1997). Business Cycle Indicators. England: Antony Rowe Ltd. REILLY, F.K.

(1989). Investment analysis and portfolio management. Florida: The Dryden Press.

RENSHAW, E. (1992). Identifying no growth years in the US economy - Using increases in crude oil prices. Energy Economics, April. 132-135. RENWICK, R.B. (1971). Introduction to Investment and Finance. New York: Macmillan. 


\section{openUP}

SHBIKAT, G. (2000). Arkansas Index of Economic Indicators. Arkansas Business and Economic Review, Vol. 33, No. 3.11-14. SNYMAN, G.J.J. (1994). The development of leading indicators for the South African building industry using qualitative and quantitative data. UCT, Unpublished PhD thesis.

STOCK-WATSON EXPERIMENTAL INDEXES: Background Information.

http://ksghome.harvard.edu/ Jstock.Academic.Ksg/xri/rpress4.htm 